\title{
ИНСТРУМЕНТАРИЙ ФИНАНСИРОВАНИЯ ИННОВАЦИОННЫХ ПРОЕКТОВ В ПРОМЫШЛЕННОСТИ
}

\author{
(c) 2019 Терпугов Артем Евгеньевич \\ аспирант \\ МИРЭА - Российский технологический университет, Россия, Москва \\ E-mail: artemterpugov@yandex.ru
}

В работе раскрывается инструментарий финансирования инновационных проектов в промышленности. Данная тематика становится актуальной в разрезе влияния на эффективность инвестиционных проектов. Целью работы является выявление оптимального инструментария финансирования инновационных проектов, который способствует увеличению эффективности деятельности и особенно благоприятен для развития инвестиционных проектов в промышленности.

Ключевые слова: финансирование, инновационный проект, промышленность, инвестиционный проект, инновационные фонды.

Российский бизнес столкнулся лицом к лицу с существенными вызовами, которые породили кризисные явления в экономике. Рентабельность отдельных секторов промышленности России находится ниже уровня инфляции. При этом всё также особняком стоит проблема невысокой производительности труда, которая в среднем ниже производительности стран, входящих в Организацию экономического сотрудничества и развития (ОЭСР), в 2 раза [1].

В фокусе российского бизнес-сообщества последние годы были инновационные проекты крупных компаний. Зачастую высокотехнологические решения требуют серьёзных вложений денежных средств, что могут себе позволить только наиболее весомые игроки на рынке, имеющие в своём распоряжении целые функциональные подразделения, занимающиеся разработкой и внедрением различных ноу-хау. Немаловажным также является то, что данные компании имеют как достаточное количество собственных средств, так и могут привлечь кредитное финансирование.

Малый и средний бизнес, который попал в поле зрения федеральных национальных проектов, должен стать, как и в остальном мире, одним из основных участников механизма, способного увеличить темпы роста российской экономики выше среднемировых значений. Однако малый и средний бизнес не имеет достаточного количества собственных средств, не может похвастаться значительным обеспечением для получения кредитного финансирования, а проектное финансирование в России не столь развито. Процентные ставки при этом порой слишком велики для начинающих инноваторов.

Актуальным становится вопрос инструментария финансирования инновационных проектов в промышленности в разрезе его влияния на эффективность инвестиционных проектов. Различные виды финансирования инновационно-инвестиционных проектов оказывают разительно отличающийся эффект в каждом отдельно взятом случае. В связи с этим целью работы является выявление наиболее оптимального инструментария финансирования инновационных проектов, который в наибольшей степени способствует увеличению эффективности деятельности и особенно благоприятен для развития инвестиционных проектов в промышленности.

Под инновационным проектом принято понимать сложную систему, которая отличается комплексом взаимообусловленных и взаимоувязанных по ресурсам, срокам и исполнителям между друг другом мероприятий, которые направлены на достижение конкретных целей и задач на приоритетных направлениях развития науки и техники.

Одной из наиболее весомых проблем развития инновационно-инвестиционных проектов в промышленности остаётся недостаточное количество, а также зачастую невозможность или неспособность получения дешёвых кредитных ресурсов. Банки выставляют высокие требования к наличию собственных средств, гарантий, а также залогового обеспечения. При этом процентная ставка остаётся высокой. Однако выделяется и ряд других инструментов финансиро- 
вания инновационных проектов.

В целом, выделяются следующие инструменты: собственные средства, банковское финансирование, привлечение ресурсов инвестиционных компаний, бизнес-ангелов (частный венчурный инвестор, который обеспечивает финансовую поддержку и содействие в качестве эксперта на ранних этапах развития компании), частных компаний, в том числе и зарубежных, а также бюджетные средства в виде грантов и инвестиций фондов и корпораций с государственным участием, целью деятельности которых является финансирование наиболее привлекательных и имеющих наибольший экономический потенциал и социальную значимость проектов.

Естественным является тот факт, что не все предприниматели, да и даже крупные компании в промышленности, в нынешней ситуации в российской экономике имеют излишки ресурсов для обеспечения финансирования передовых разработок. Это отражается и на сложности в привлечении банковского финансирования, о котором говорилось выше.

Однако некоторые разработки российских компаний имеют как экономический потенциал, так и высокую социальную значимость в части решения особо острых региональных проблем, в том числе они попросту будут способствовать росту рабочих мест, производительности. Это в конечном итоге при должном масштабе отразится на увеличении покупательской способности населения и экономики. Трудно сказать, что это не выгодно государству. Поэтому правительство регулярно ищет возможности по стимулированию развития инновационно-инвестиционных проектов. В связи с этим в списке инструментария финансирования инновационных проектов в промышленности в части возможностей привлечения ресурсов особняком стоят гранты, а также государственные фонды и инвестиционные компании.

Углубляясь в изучение грантовой поддержки и проводимые в Российской Федерации конкурсы, можно отметить их огромное множество. Присутствует разделение как по размеру бизнеса, так и по отрасли, в том числе и в региональном разрезе. Однако ключевым является Фонд содействия развитию малых форм предприятий в научно-технической сфере. Как становится понятным из названия, участие в его мероприятиях подходит промышленным ком- паниям небольшого размера. В данном фонде выделяются следующие основные программы: «Умник», «Старт», «Развитие», «Интернационализация», «Коммерциализация» и «Кооперация». Максимальный размер гранта по данным программам - 25 млн. руб. Данная сумма является значимой для небольших промышленных предприятий, но зачастую может помочь лишь при инициации масштабного бизнеса [2].

Среднему и крупному бизнесу, организующему инновационные проекты в промышленности, гораздо более интересны государственные фонды. Наиболее заметными здесь являются Государственная корпорация развития «ВЭБ.РФ», АО «РВК», Российский фонд прямых инвестиций, Российский экспортный центр, Федеральная корпорация по развитию малого и среднего предпринимательства, Фонд развития промышленности, Фонд развития моногородов, инвестиционные фонды Роснано.

Среди этих фондов реализуются различные программы по развитию, под которое обеспечивается финансирование. Самой известной из них является Национальная технологическая инициатива, которая представляет из себя программу мер по формированию принципиально новых рынков и созданию условий для глобального технологического лидерства России к 2035 году: Аэронет, Автонет, Маринет, Нейронет, Хелснет, Фуднет, Энерджинет, Сэйфнет, Финнет и Медианет. Проектный офис Национальной технологической инициативы организован на базе PBК.

Однако в большинстве своём действия фондов не ограничиваются какой-либо определённой программой. Финансирование инновационно-инвестиционного проекта, в том числе и в промышленности, зависит от условий конкретного фонда. Если Фонд развития промышленности и Федеральная корпорация по развитию малого и среднего предпринимательства ориентированы на предоставление заёмного финансирования, а Российский экспортный центр на страховой поддержке экспорта и финансировании экспортных операций, то ВЭБ.РФ, РВК, Российский фонд прямых инвестиций, Фонд развития моногородов, инвестиционные фонды Роснано могут непосредственно заниматься инвестициями в инновационные проекты в промышленности.

Размер финансирования также может быть абсолютно различным. Если Фонд развития мо- 
ногородов ограничивает свои вложения 1 млрд. рублей [3], то ВЭБ.РФ установил минимальный совокупный размер своего участия в 500 млн. рублей (при стоимости проекта свыше 1 млрд. рублей) [4].

Также существенным драйвером для инновационно-инвестиционных проектов может стать государственно-частное партнёрство. В мировой практике выделяются следующие виды государственно-частного партнёрства: Build, Operate, Transfer (Построй-Управляй-Передай концессионный механизм, право пользования (без права собственности частного партнёра)), Build, Own, Operate, Transfer (Построй-Владей-Управляй-Передай - право собственности на время действия контракта), Build, Transfer, Operate (Построй-Передай-Управляй - частный партнёр обслуживает объект в течение срока действия соглашения), Build, Own, Operate (Построй-Владей-Управляй - объект остаётся в собственности частного партнёра), Build, Operate, Maintain, Transfer (Построй-Управляй-Поддерживай-Передай - поддержка жизнеспособности и обслуживании объекта), Design, Build, Own, Operate, Transfer (Спроектируй-Построй-Владей-Управляй-Передай - в обязанности частного партнёра входит проектирование объекта соглашения), Design, Build, Finance, Operate (Спроектируй-Построй-Финансируй-Управляй - в обязанности частного партнёра входит финансирование строительства и мероприятия по обслуживанию). В российской практике особо выделяются концессионные соглашения, так как взаимоотношения и выгоды сторон в данном случае наиболее понятны российскому бизнесу, схемы взаимодействия уже отточены на практике.

В этом же аспекте стоит отметить развитие в последние годы в Российской Федерации механизма специальных инвестиционных контрактов. При минимальном объёме инвестиций в размере 750 млн. рублей инвестор имеет право на неухудшение налоговых условий, налоговые льготы, получение статуса «Made in Russia» на продукцию с отлагательным условием по локализации, доступ к государственному заказу, на создание субъектами Российской Федерации объектов инфраструктуры и особые условия аренды земельных участков. Одними из первых в данном направлении начали работать в г. Москва. Было принято две модели стимулирования спроса: через специальный инвестиционный контракт (СПИК), в результате чего произво- дитель может получить выгоду от инвестиций посредством признания в качестве единственного поставщика, и через офсетную сделку, где контракт на поставку заключается при условии выполнения требований по созданию производства.

Зачастую как инструмент финансирования выделяют государственные субсидии в промышленности. Субсидии получаются по факту произведённых затрат. В связи с этим для приобретения или постройки объекта первоначально необходимо изыскать ресурсы. Но субсидия может быть в дальнейшем использована в качестве финансирования инновационного проекта.

Таким образом, можно отметить, что инструментарий государственного финансирования инновационных проектов в промышленности в Российской Федерации развивается. Сроки рассмотрения заявок на финансирование проектов постоянно сокращаются, однако зачастую они связаны с длительными проверками, которые требуют значительного ожидания. Объём средств, как и в любых инвестиционных фондах ограничен, в связи с чем отбор происходит весьма тщательно. Вхождение в капитал инновационного проекта государственной компании выливается в свои особенности управления организацией и предоставления отчётности. Это может привлекать не всех. Данный тип предпринимателей обращаются к инструментам частного финансирования.

В последние годы частное финансирование в России стало получить сложнее. Это связано с негативными кризисными явлениями в экономике. Инвесторов, имеющих свободные финансовые ресурсы и готовых их вкладывать в перспективные проекты, стало меньше. Многие из них стали направлять ресурсы на борьбу с проблемами в своих уже существующих организациях.

Предприниматели, реализующие инновационные проекты в промышленности, особенно где требуются серьёзные капитальные вложения, оказались не в самом выгодном положении. Однако стартапы остаются всё также привлекательными. Венчурные инвестиции, представляющие собой высокорисковые вложения в новые, растущие или борющиеся за место на рынке организации, предполагают сверхдоходы. Инвестиционные фонды и бизнес-ангелы инвестируют в различные организации, бизнес-модель которых пока не отработана, но имеет потенциал к 
масштабированию, т.е. стартапы.

Бытует распространённое мнение, что 9 из 10 стартапов погибают в первый год работы. По данным исследования Fleximize, через 5 лет после инициации остаются в живых 49\% стартапов [5]. Однако ключевым здесь является, что они именно «остаются в живых». Сверхдоходы приносят не более 1 из 10 стартапов, а уж становятся «единорогами» (стартапами с капитализацией выше 1 млрд. долларов США) ещё меньше. А именно этого и добиваются в своих инвестициях венчурные инвестиционные фонды. Они имеют широкий портфель проектов, понимая, что возможно только один из этих проектов станет сверхдоходным, но именно он максимально окупит весь остальной портфель. Венчурные инвесторы высоко ценят роль команды проекта и идеи. Порой здесь важен именно момент инвестирования, который можно упустить.

Другой подход используют традиционные инвесторы. Они более консервативные в оценках, используют фундаментальные способы оценки проектов. Происходит тщательный, доскональный анализ проекта: предпосылок его реализации, детального бюджета, предполагаемой динамики выручки и её составляющих, капитальных и операционных затрат, возможной потребности в привлечении дополнительных финансовых ресурсов в будущем, всевозможных рисков, прогнозов бухгалтерского баланса, финансовых результатов, движения денежных средств и дисконтированных денежных потоков, детально проработанного бизнес-плана, информации о собственниках и прочих документов. Инвесторы максимально изучают проект перед принятием решения об инвестициях, затрачивают на анализ длительное время, предпочитая уже работающий бизнес для вложений. Однако при этом абсолютно понятно, что сверхдоходов здесь ожидать не стоит, но при этом и риски гораздо ниже.

При этом не стоит упускать из виду банковское финансирование. Банки схожи с традиционными инвесторами. Для них также максимально важным являются всевозможные регистрационные документы компании, данные собственников, детальный бизнес-план и финансовая модель проекта, его максимальное обоснование, текущее финансовое состояние компании и множество других показателей. При этом банк может потребовать обеспечение в виде залогов, в том числе и внесение опреде- лённого количества денежных средств на депозит, предоставление гарантий, поручительств. Помимо данных основных видов обеспечения кредита банки могут нивелировать риски также и другими способами.

В виду вышеперечисленных требований получить кредитное финансирование могут себе позволить в основном лишь уже действующие организации. Для инновационных проектов в промышленности в этом случае может быть интересен прочий инструментарий банковского финансирования.

Проектное финансирование предполагает долгосрочное финансирование крупных проектов путём их кредитования под денежный поток, создаваемый проектом. При этом проектное финансирование может быть с полным регрессом на кредитозаёмщика (кредитозаёмщик берёт на себя все связанные с проектом риски), без регресса на кредитозаёщика (кредитор отвечает за все возможные риски), с ограниченным регрессом на кредитозаёмщика (происходит перераспределение рисков между участниками). Процесс работы банка в этом случае имеет множество схожих черт с деятельностью инвестора. Требуется более тщательное рассмотрение заявки, чем при обычном займе, в связи с этим сроки анализа являются более длительными.

При повышенном профиле риска сделки возможно применение мезонинного кредитования. Мезонинное кредитование - вид заёмного финансирования, при котором вложения в проект происходят на условиях получения доли в организации за конкретную стоимость при определённых условиях. Дополнительная доходность компенсирует повышенный риск. Она может быть реализована посредством опционов на определённый пакет акций, а также через повышенную процентную ставку, которая выплачивается после выполнения инвестиционной программы.

Обеспечить финансирование проекта также возможно путём выпуска ценных бумаг или получения заёмного финансирования от организации, которая не является банком. Однако это уже частные случаи, которые зачастую не доступны большинству организаций на рынке.

При всём богатстве инструментария финансирования инновационных проектов в промышленности остаётся несколько серьёзных проблем. Разве только финансирование инвестиционного проекта собственными средствами не требует 
широкого обоснования. Зачастую бизнес-ангелы и венчурные фонды оказывают экспертную поддержку в развитии инновационного проекта. Но большинству частных инвесторов, государственных инвестиционных фондов, банков требуется детальное обоснование проекта. То же касается и получения субсидий. Этот анализ требует серьёзный знаний, умений и навыков не только в технологическом аспекте разработанного нового продукта или оборудования, но и в экономическом, а также юридическом аспектах.

Множество инициатив и идей разбиваются об эти преграды. Разработки являются уникальными, но инициатор инновационного проекта не может вывести его на рынок, не говоря о масштабировании. Обширные пакеты документов не только помогают оценить риски, но и позволяют проанализировать способности инициатора к управлению проектом. В большинстве случаев те, кто не способен предоставить все эти документы, могут иметь проблемы, связанные с экономикой проекта. При использовании инструментария финансирования проектов в промышленности важно обладать фундаментальными знаниями в экономике и менеджменте, особенно в части управления проектами, в том числе финансовом менеджменте, при этом имея представление о юридической стороне вопроса. Только такой широкий спектр позволит профинансировать и успешно реализовывать инновационные проекты в промышленности.

\section{Библиографический список}

1. Исследование уровня ВВП на душу населения и производительности Организации экономического сотрудничества и развития (ОЭСР). URL: https://stats.oecd.org/index.aspx?queryid=54563 (дата обращения: 17.03.2019).

2. Информация о программах Фонда содействия развитию малых форм предприятий в научно-технической сфере. URL: http://fasie.ru/programs/ (дата обращения: 17.03.2019).

3. Информация о параметрах участия Фонда развития моногородов в финансировании инвестиционных проектов. URL: http://xn-80afd4affbbat.xn - p1ai/work/products/invest-projects/ (дата обращения: 17.03.2019).

4. Информация о параметрах участия ВЭБ.РФ в финансировании инвестиционных проектов. URL: https:// xn-90ab5f.xn - p1ai/biznesu/finansirovaniye-proyektov/vysokiye-tekhnologii-i-innovatsii/ (дата обращения: 17.03.2019),

5. Исследование компании Fleximize о динамике выживаемости стартапов. URL: https:/fleximize.com/ business-survival/ (дата обращения: 17.03.2019). 